This item was submitted to Loughborough's Research Repository by the author.

Items in Figshare are protected by copyright, with all rights reserved, unless otherwise indicated.

\title{
Onset of cellular instabilities in spherically propagating hydrogen-air premixed laminar flames
}

PLEASE CITE THE PUBLISHED VERSION

http://dx.doi.org/10.1016/j.ijhydene.2012.05.013

PUBLISHER

(C) Elsevier

VERSION

AM (Accepted Manuscript)

\section{PUBLISHER STATEMENT}

This work is made available according to the conditions of the Creative Commons Attribution-NonCommercialNoDerivatives 4.0 International (CC BY-NC-ND 4.0) licence. Full details of this licence are available at: https://creativecommons.org/licenses/by-nc-nd/4.0/

\section{LICENCE}

CC BY-NC-ND 4.0

\section{REPOSITORY RECORD}

Liu, Fushui, Xiuchao Bao, Jiayi Gu, and Rui Chen. 2012. "Onset of Cellular Instabilities in Spherically Propagating Hydrogen-air Premixed Laminar Flames”. figshare. https://hdl.handle.net/2134/10532. 


\title{
Onset of Cellular Instabilities in Spherically Propagating Hydrogen-Air \\ Premixed Laminar Flames
}

\author{
Fushui Liu, Xiuchao Bao
}

School of Mechanical and Vehicular Engineering, Beijing Institute of Technology, China

\author{
Jiayi Gu,Rui Chen
}

Department of Aeronautical and Automotive Engineering, Loughborough University, UK

\section{Correspondence author's current contact information:}

Professor Rui Chen

Department of Aeronautical and Automotive Engineering

Loughborough University

Loughborough,

Leicestershire, LE11 3TU,

UK

Tel: +44-(0)1509-227255

Fax: +44-(0)1509-227275

e-mail: R.Chen@lboro.ac.uk 


\section{Abstract:}

Using high-speed Schlieren and Shadow photography, the instabilities of outwardly propagating spherical hydrogen-air flames have been studied in a constant volume combustion bomb. Combustion under different equivalence ratios $(0.2 \sim 1.0)$, temperatures $(298 \mathrm{~K} \sim 423 \mathrm{~K})$ and pressures $(1.0 \mathrm{bar} \sim 10.0 \mathrm{bar})$ is visualized. The results show that flames experience both unequal diffusion and/or hydrodynamic instabilities at different stages of propagation. The critical flame radius for such instabilities is measured and correlated to the variations of equivalence ratio, temperature and pressure. Analysis revealed that equivalence ratio affects unequal diffusion instability via varying the Lewis number, $L e$; increased temperature can delay both types of instabilities in the majority of tests by promoting combustion rate and changing density ratio; pressure variation has minor effect on unequal diffusion instability but is responsible for enhancing hydrodynamic instability, particularly for stoichiometric and near-stoichiometric flames.

\section{Keywords:}

Hydrogen combustion, Premixed Laminar flames, Flame instabilities, Onset of cellular instabilities, Combustion bomb 


\section{Introduction}

The Hydrogen-fuelled Internal Combustion Engine (HICE) offers the potential of solving the energy crisis and engine-out emission problems. The performance and emission characteristics of a spark ignition HICE are dominated by the premixed turbulent combustion process. Laminar flames can be used to validate the chemical reaction mechanisms and to gain a fundamental understanding of the turbulent combustion process. Therefore, it is necessary and essential to study the characteristics of hydrogen-air laminar flames.

Many researchers have investigated the hydrogen-air laminar combustion. Edmonds et al. [1] reported the laminar burning velocity of hydrogen-air flames under different equivalence ratios; Stephenson et al. [2] did measurements on a wider range of the laminar burning velocity at atmospheric pressure; Law et al. [3] measured the laminar burning velocity of hydrogen-air flames with hydrocarbon dilutions using Laser-Doppler anemometry and Schlieren photography from a constant-velocity nozzle burner under 1 bar; Milton et al. [4] and lijima et al. [5] extracted the laminar burning velocities from pressure measurements in a constant volume combustion bomb under different initial equivalence ratios, temperatures and pressures. The flame stretch effects were ignored in the above experimental research.

Koroll et al. [6] measured the burning velocity of hydrogen-air-steam jet flames using the double-kernel technique and Schlieren photography; Tse et al. [7] studied hydrogen-oxygen flames under elevated temperatures and pressures; Dahoe et al. [8] measured the burning velocity from pressure variations in a windowless explosion vessel. Ilbas et al. [9] studied the hydrogen-methane-air flames under ambient temperature and different equivalence ratios using combustion bomb with optical access. The rig comprises a $250 \mathrm{~mm}$ long cylindrical stainless steel explosion bomb enclosed at one end with a stainless steel plug which houses an internal stirrer to allow mixing. The other end is sealed with a $120 \mathrm{~mm}$ diameter round quartz window. Numerically, Williams et al. [10] developed a model that offered a new 
perspective on laminar flame propagation of lean hydrogen-air mixtures diluted by highly diffusive fuels. Although some of the above research takes into account the relationship between laminar burning velocities and flame stretch effect, some of the flame speed characteristics still cannot be properly explained. The theories of flame instabilities were not included in these laminar flame propagation studies.

Flame instabilities play an important role in spherical outwardly propagating flames, particularly in lean hydrogen-air flames $[11,22]$. Faeth et al. $[12,13,14]$ studied the conditions that caused the destabilization of stable flames and categorized three kinds of instabilities whose effects are the most significant; Bradley et al. [15,16,17], Tang et al. [18] and Hu et al. [19] did further research on the formation schemes of cellular flame structures, the critical radius and the Peclet numbers during spherical flame propagation; Kwon et al. [20] reported major parameters that affect flame instabilities. However, these studies did not make further investigations into the regularity of flame instabilities under a wider range of experimental conditions.

The present work focuses on the systematic studies of the onset of hydrogen-air flame instabilities, which is defined by the critical flame radius, and its relationships with equivalence ratio, temperature and pressure. The aim of current research is to:

(1) Experimentally identify the critical radius for the onset of instabilities of hydrogen-air flames, and,

(2) Systematically examine the effects of temperature, pressure and equivalence ratio on the variation of the critical radius.

\section{Cellular Instabilities of Spherical Flames}

According to the mechanism that triggers the instabilities of laminar flames two main kinds of instabilities are defined and studied: unequal diffusion instability and hydrodynamic instability [11-19]. A third category, buoyant instability, caused by gravitational effect, can also be 
found in previous research $[20,21]$. It is often neglected as its effect on rapidly propagating flames is minor compared to the other two categories of instabilities.

\subsection{Unequal diffusion instability}

The unequal diffusion instability is often referred to as thermal-diffusive instability. During the flame propagation process, both mass and thermal diffusions exist across the flame surface. The energy ratio of the two kinds of diffusion is expressed by the Lewis Number, Le:

$L e=\frac{D_{T}}{D_{i M}}$

where $D_{T}$ is the thermal diffusivity of the unburnt mixture:

$D_{T}=\frac{\lambda}{\rho_{u} c_{p}}$

where $\lambda$ is the unburnt gas thermal conductivity, $\rho_{u}$ is the unburnt gas density and $C_{p}$ is the specific heat at constant pressure. And, $D_{i M}$ is the mass diffusivity of the deficient reactant (e.g. fuel in lean flames, oxygen in rich flames):

$D_{i M}=\left(\sum_{j=1}^{n} V_{j} / D_{i j}\right)^{-1}$

where $i$ indicates the limiting reactant, $V_{j}$ is the volume fraction of species $j$ and $D_{i j}$ is the mass diffusivity of the deficient reactant relative to the species $j$.

When $L e>1$, the thermal diffusion exceeds the mass diffusion and the swelling parts of the flame surface lose heat energy more rapidly than the mass diffusion of the deficient reactant can compensate for. Therefore the net energy flow would be negative. As a result, the flame temperature gradually falls below the adiabatic temperature and the burning velocity reduces. The concave parts, on the contrary, gain positive net energy due to stronger mass diffusion of the deficient reactant than the energy loss by thermal diffusion. Consequently, flame temperature and burning velocity both increase. In general, the decelerating and 
accelerating effects induced, respectively, in the swelling and concave parts cancel each other out, and the flame surface maintains its smoothness and stability [22].On the other hand, when $L e<1$, both the swelling and concave parts will be enhanced, and therefore the flame rapidly loses its surface smoothness. Such instability often occurs in the early stage of flame propagation when $L e<1$ andcan be identified by irregular distortions of the flame surface (Fig. 1)

\subsection{Hydrodynamic instability}

In some occasions, although the flame can maintain $L e>1$ it still undergoes cellular instability in the later stage of its propagation. This instability was first studied by Darrieus and Landau [23]. In their research the flame is seen as a density discontinuity and the formation mechanism of such instability is described as the interactions between the hydrodynamic disturbances generated by the flame and the flame itself. Additionally, hydrodynamic instability is also responsible for flame surface wrinkling [20]. Such instability can be distinguished when the flame radius is large enough and the diffusion stability cannot offset its effect. It can be identified by the regular cellular distortions of the flame surface (Fig. 2).

During any flame propagation processes, hydrodynamic instability always exists. Its intensity is directly proportional to density ratio, $\sigma$, of the burned and the unburnt gas, and inversely proportional to flame thickness $\delta$.

$$
\begin{aligned}
& \sigma=\frac{\rho_{u}}{\rho_{b}} \\
& \delta=\frac{v}{u_{l}}
\end{aligned}
$$

where $v$ is unburnt gas kinematic viscosity; $u_{\mathbb{l}}$ is unstretched laminar burning velocity.

\section{Experimental Studies}


The experimental rig used for current research is composed of six main parts: the constant volume combustion bomb (with a temperature control device); optical access system (Schlieren and Shadow photography system); fuel and oxidizer intake system; ignition system; data acquisition and control system and high-speed photography system as illustrated in Fig. 3. The stainless steel combustion bomb has a $400 \mathrm{~mm}$ inner diameter and extensive optical access through a pair of quartz windows of $100 \mathrm{~mm}$ diameter. Fresh mixtures in the combustion bomb can be uniformly heated by resistance wires inside. The combustible mixture is spark ignited using spark plug. The optical system is arranged into a Z-shape, comprising two curved primary mirrors of $100 \mathrm{~mm}$ diameter and focal length of 100 $\mathrm{cm}$. Gas temperature inside the bomb is obtained from two chrome-alumel thermocouples. Pressure is measured during the explosion with a Kistler pressure transducer. Flame images are recorded by a TRI Phantom v7.3 camera which is capable of a maximum speed of 200,000 frames per second.

In most flame propagation processes, two distinctive instants at which flame surfaces lose initial smoothness can be found:

- Large cracks on the flame surface begin to branch and the formation of cracks in new directions, as illustrated by the $4^{\text {th }}$ images of Fig. 4 . The reason for the formation of these cracks can be unequal diffusion instability, un-even distribution of spark energy and local unburnt mixture inhomogeneity.

- Sudden and spontaneous appearance of a large number of small cells over the entire flame surface (the $5^{\text {th }}$ image of Fig. 4). The characteristic length scale of such cells is significantly smaller than that of those large cracks. The appearance of these small cells is caused by hydrodynamic instability.

In the analysis below, the second instant will be used primarily as the onset of flame instability, unless significant unequal diffusion instability can be identified earlier. The reason being: firstly, unlike the unequal diffusion instability, hydrodynamic instability occurs in 
almost all flame propagations. Secondly, compared to the gradual growth and branching of the large cracks, the hydrodynamic instability occurs with very high intensity, i.e. small cells grow across the entire flame surface spontaneously, making it relatively easier to accurately identify the exact onset timing. Additionally, the values of $L e, \sigma$ and $\delta$ are calculated based on initial temperature, pressure and equivalence ratio prior to ignition.

\section{Results and Discussion}

The following effects of fuel to air equivalence ratio, temperature, and pressure have been measured and discussed. In order to eliminate the effect of difference in bomb size, the critical timing of onset of instabilities is represented by 'normalised critical flame radius' which is defined as the ratio of critical flame radius and the bomb radius: $R_{f} / R_{b o m b}$.

\subsection{Effect of Fuel to Air Equivalence Ratio}

Fig. 5 to Fig. 7 shows the measured effect of equivalence ratio on the flame instabilities. A common characteristic found in all three figures is that, despite the increase in initial temperature, the flame tends to lose stability earlier under leaner conditions and becomes progressively more stable as the equivalence ratio moves towards stoichiometry. Such behaviours are expected as lean and stoichiometric/rich hydrogen-air flames, respectively, are naturally unequal diffusion instable $(L e>1)$ and stable $(L e<1)$.

Fig. 8 shows the variation of the Lewis number, calculated using Equation (1), under different equivalence ratios, temperatures and pressures. Lean hydrogen-air mixtures have low Lewis numbers and therefore are prone to unequal diffusion instability, especially when $\Phi=0.2$ that the propensity to destabilize is so strong such that the flame stretch effect cannot offset the destabilization effect and stabilizes the flame; the flame surface loses uniformity at a very early stage of propagation as shown in Fig. 2.

Equivalence ratio affects the flame instabilities primarily by reducing and enhancing the propensity to unequal diffusion instability. For lean hydrogen-air flames unequal diffusion 
instability occurs in the early stage of flame propagation before any signs of the hydrodynamic instability can be observed. On the other hand, stoichiometric and rich hydrogen-air flames naturally have Lewis numbers that are greater than unity and thus have higher resistance to unequal diffusion instability. In experimental observations, these flames can maintain uniformity to a later stage of propagation before hydrodynamic instability is triggered. In general, equivalence ratio affects the flame instability under lean-burn conditions and at the early stage of flame propagation. Flame stability becomes less sensitive to equivalence ratio when $\Phi$ gradually moves towards stoichiometry.

\subsection{Effect of Temperature}

The effects of temperature on the flame instabilities are shown in Fig. 9 and Fig. 10. Graphically these effects can be split into two categories: effect on lean flames ( $\Phi=0.2,0.4)$ and effect on near-stoichiometric to stoichiometric flames $(\Phi=0.8,1.0)$. For lean flames, the increased temperature can, especially under lower pressure, delay the occurrence of unequal diffusion instability. The reason could be that very lean flames $(\Phi=0.2,0.4)$ always suffer from slow burning speed. Such slow propagation gives cracks that are formed by either initial spark defects and local inhomogeneity or unequal diffusion effect plenty of time to grow and branch. By increasing the temperature the combustion is greatly intensified, so is the burning speed. This increase in burning speed is particularly significant in very lean flames. It greatly reduces the time for the cracks to form and grow. Therefore the flames retain their relative smoothness for a longer time ('relative' means that very lean flames are often 'born' with large cracks due to unequal diffusion instability).

For stoichiometric and near stoichiometric flames $(\Phi=0.8,1.0)$ the above-mentioned delaying effect of increasing temperature is also noticeable. These flames are either naturally unequal diffusional stable or have much stronger resistance to unequal diffusion instability compared to leaner flames; therefore, it is logical to say that increased temperature stabilizes flames from the hydrodynamic instability. The calculated density ratio, 
$\sigma$, using Equation (4) and shown in Fig. 11, revealed that $\sigma$ is inversely proportional to temperature, which means that propensity to hydrodynamic instability is reduced as the temperature is increased.

Contradictorily, when the combustion occurs in a more highly compressed environment the delaying effect is completely levelled off for very lean flames or even reversed for stoichiometric and near stoichiometric flames. It suggests that temperature is not the dominant factor for the onset of flame instabilities.

\subsection{Effect of Pressure}

Under lower pressure (1 bar), flames of different equivalence ratios show good consistence in terms of unequal diffusion instability i.e., lean hydrogen flames $(\Phi=0.2,0.4)$ lose stability very early; when the mixture is enriched to $\Phi=0.8$ the flame shows much better resistance to unequal diffusion instability, but still loses surface smoothness much sooner than stoichiometric flame which is naturally unequal diffusional stable and eventually breaks up due to hydrodynamic destabilization, as shown in Fig. 12.

As the pressure builds up all flames exhibit much earlier destabilization, particularly the stoichiometric and near-stoichiometric flames. Very lean flames $(\Phi=0.2,0.4)$ experience relatively less advances in destabilization. That is to say, it is the hydrodynamic instability rather than the unequal diffusion instability that has been more significantly enhanced. However, since the Lewis number, $L e$, and density ratio, $\sigma$, are almost unchanged with pressure variation (shown in Fig. 8 and Fig. 11 respectively), neither unequal diffusion nor hydrodynamic instability, in theory, should be enhanced by the increase of pressure. Therefore another parameter must be responsible for the advance in destabilization. Fig. 13 shows the variations of flame thickness, $\delta$, calculated by Equation (5). It can be clearly seen that $\delta$ is stable against temperature change but is more sensitive to pressure increase i.e., the flame becomes thinner as pressure increases. A thinner flame usually indicates 
intensified combustion and faster flame speed but it also results in lower tolerance to both internal and external disturbances, making the flame more vulnerable to destabilization. The same characteristic was also summarized in the work by Law et al. [20]. Therefore it is logical to say that thinner flames tend to promote early hydrodynamic instability, as shown in Fig. 14. Also found from Fig. 14 is that as the flame front becomes thinner the number of cells increases and the average size of cells decreases.

\section{Conclusions}

The onset of flame instabilities of laminar hydrogen-air spherical premixed flames has been studied in a constant volume combustion bomb using high-speed Schlieren and Shadow photography techniques. The effects of equivalence ratio, temperature and pressure were identified and analysed. The following conclusions can be drawn based on the analysis of experimental results:

- Outwardly propagating spherical flames experience two categories of instabilities: unequal diffusion instability caused by unequal mass and thermal diffusion, and hydrodynamic instability caused by interactions between the flame and external disturbances.

- Unequal diffusion instability can be visually identified by the gradual growth and branching of the large cracks. Its appearance is governed by the Lewis number. Stoichiometric hydrogen flames are naturally stable to unequal diffusion instability.

- Hydrodynamic instability can be visually identified by the sudden and spontaneous appearance of small cells across the entire flame surface. Changes to certain parameters can only delay the appearance but not totally eliminate it.

- The onset of flame instabilities is identified by the means of measuring critical flame radius. The critical radius is proven to be under the influences of equivalence ratio, temperature and pressure. 
- Equivalence ratio governs the value of the Lewis number, Le, and therefore decides whether the flame is naturally stable or instable to unequal diffusion instability. When $L e<1$, cells induced by unequal diffusion effect grow instantaneously at the beginning of flame kernel formation.

- Increased temperature has a strong delaying effect on the appearance of unequal diffusion cells, particularly for very lean flames. The reason could be enhanced combustion rate and flame speed that allow less time for the cells to appear and grow. For stoichiometric flames, temperature increase reduces the density ratio, $\sigma$, and therefore weakens the hydrodynamic instability.

- Experimental results revealed that pressure is the most dominant of the three parameters under investigation in terms of the onset of flame instability. Although pressure variation barely affects either $L e$ or $\sigma$ which means it does not enhance unequal diffusion and hydrodynamic instabilities, but it affects the flame in a more direct manner: by changing the flame thickness. Increased pressure significantly weakens the flame front making it more vulnerable to destabilization. Higher pressure also induces a larger number of cells of smaller average size.

\section{FIGURE LEGEND:}

Fig.1 Evolution of unequal diffusion instability at 298K, 1bar, $\Phi=0.2$

Fig.2 Evolution of hydrodynamic instability at $298 \mathrm{~K}, 1 \mathrm{bar}, \Phi=1.0$

Fig.3 Schematic diagram of experiment devices setup.

Fig.4 Serial images of propagation process of hydrogen-air flame at $298 \mathrm{~K}, 1 \mathrm{bar}, \Phi=1.0$

Fig.5 Normalized Critical Flame Radius under different equivalence ratio at an initial temperature of $298 \mathrm{~K}$

Fig.6 Normalized Critical Flame Radius under different equivalence ratio at an initial temperature of $348 \mathrm{~K}$ 
Fig.7 Normalized Critical Flame Radius under different equivalence ratio at an initial temperature of $423 \mathrm{~K}$

Fig.8 Calculated Lewis Number under different equivalence ratio, temperature and pressure Fig.9 Critical Flame Radius under different temperature at an initial pressure of 1 bar Fig.10 Critical Flame Radius under different temperature at an initial pressure of 2 bar Fig.11 Calculated density ratio under different equivalence ratio, temperature and pressure Fig.12 Critical Flame Radius under different equivalence ratios and pressures at an initial temperature of $298 \mathrm{~K}$

Fig.13 Measured Flame Thickness at different equivalence ratio, temperature and pressure Fig.14 Schlieren photographs of burning sequences of stoichiometric hydrogen-air flames at 298K 1bar (upper row) and 2bar (lower row) at the same time after ignition: $1 \mathrm{~ms}, 1.4 \mathrm{~ms}$, $2.5 \mathrm{~ms}$ and $3 \mathrm{~ms}$ 


\section{FIGURES:}
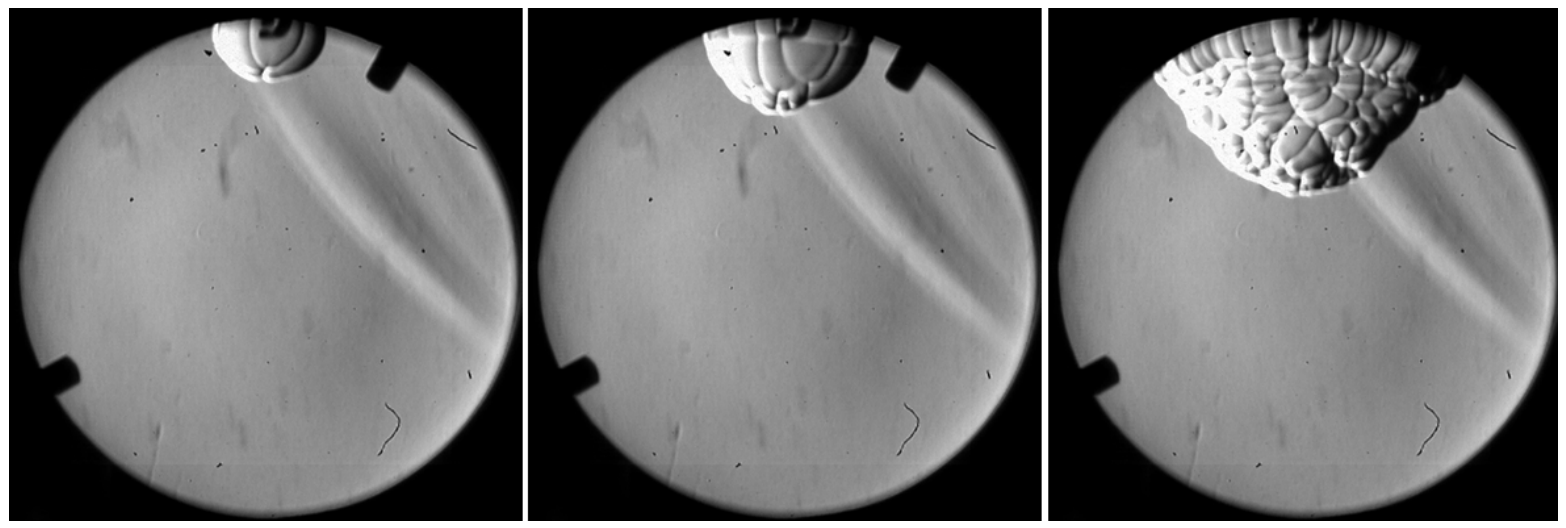

Fig.1 Evolution of unequal diffusion instability at $298 \mathrm{~K}, 1 \mathrm{bar}, \Phi=0.2$.

Measurement times are (from left to right): $0.0069 \mathrm{~s}, 0.013 \mathrm{~s}$ and $0.030 \mathrm{~s}$.
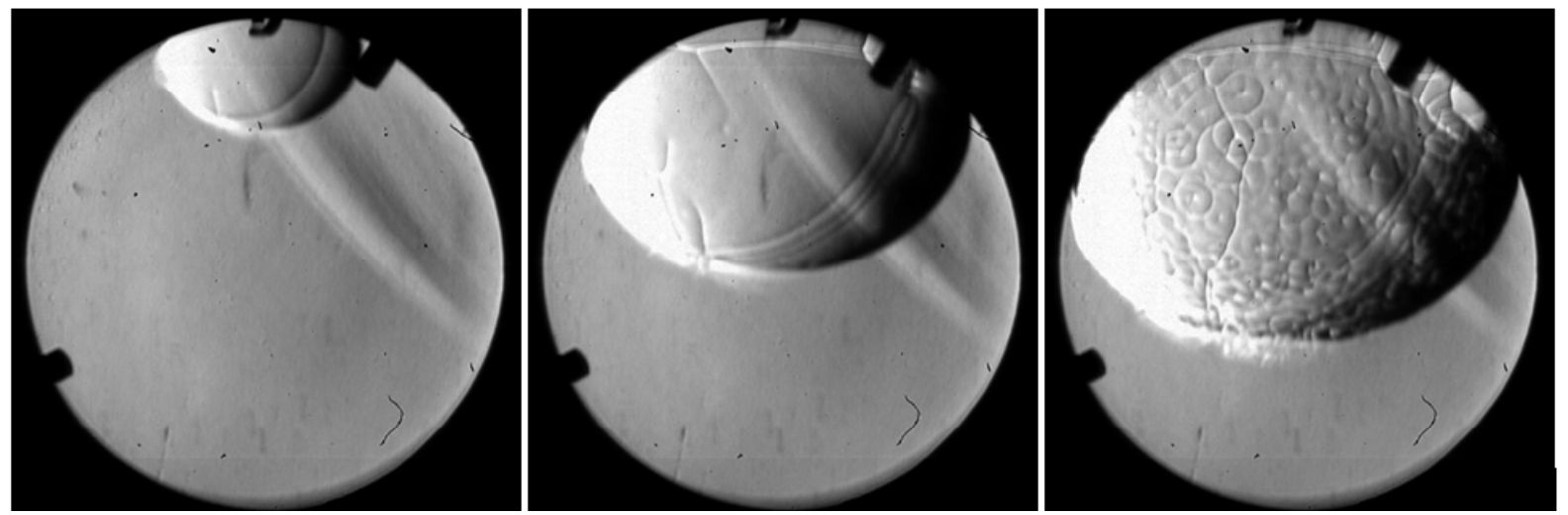

Fig.2 Evolution of hydrodynamic instability at 298K, 1bar, $\Phi=1.0$.

Measurement times are (from left to right): $0.0014 \mathrm{~s}, 0.0029 \mathrm{~s}$ and $0.0036 \mathrm{~s}$.

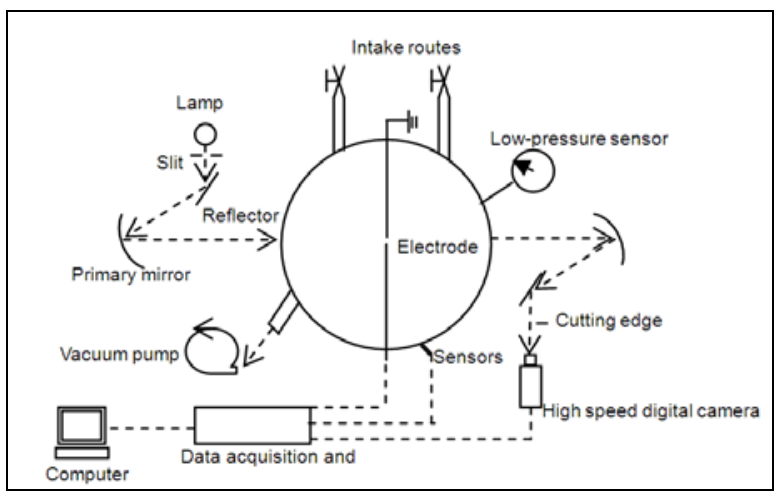


Fig.3 Schematic diagram of experiment devices setup.

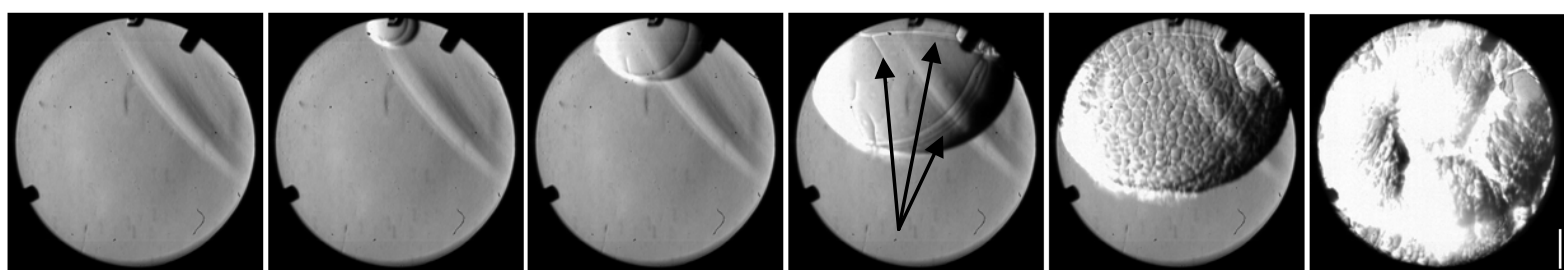

Fig.4 Serial images of propagation process of hydrogen-air flame at $298 \mathrm{~K}, 1 \mathrm{bar}, \Phi=1.0$.

Measurement times are (from left to right): $0.00038 \mathrm{~s}, 0.00077 \mathrm{~s}, 0.0015 \mathrm{~s}, 0.0030 \mathrm{~s}, 0.0038 \mathrm{~s}$ and $0.0045 \mathrm{~s}$. Black arrows in $4^{\text {th }}$ image indicate 'large cracks'.

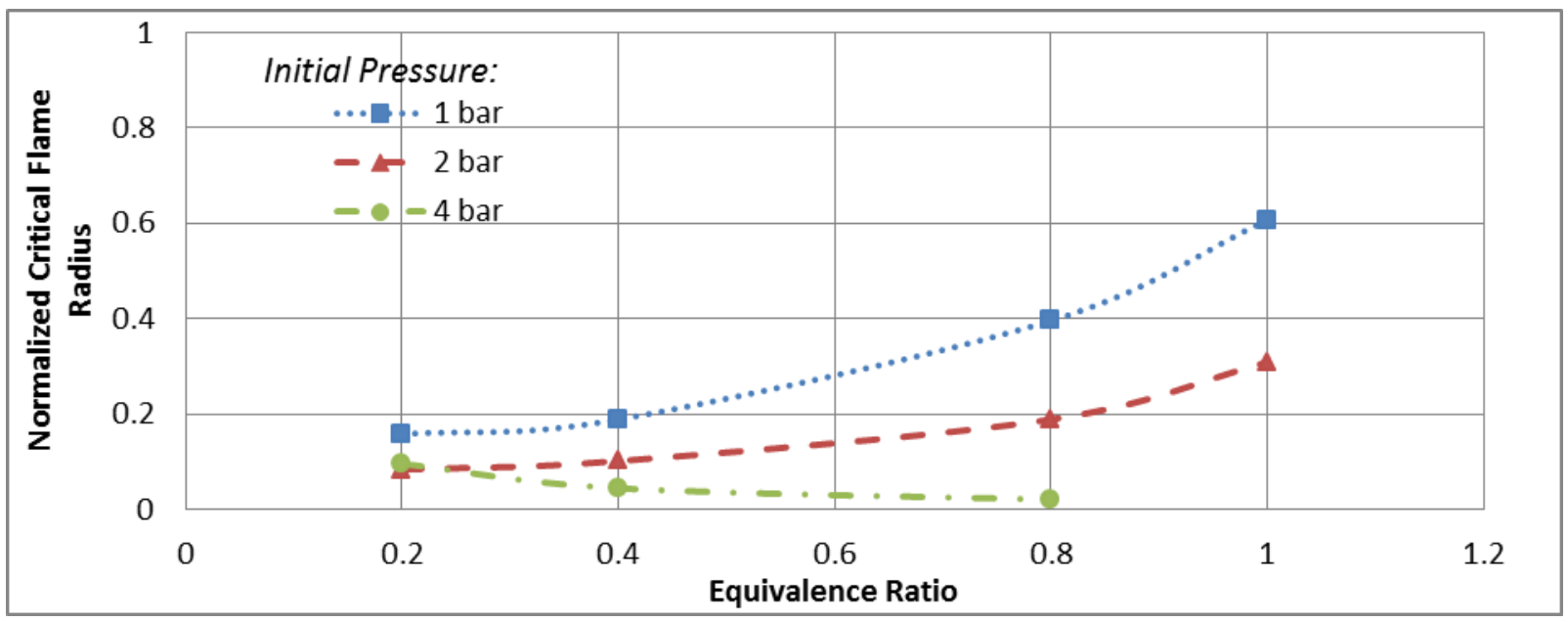

Fig.5 Normalized Critical Flame Radius under different equivalence ratio at an initial temperature of $298 \mathrm{~K}$ 


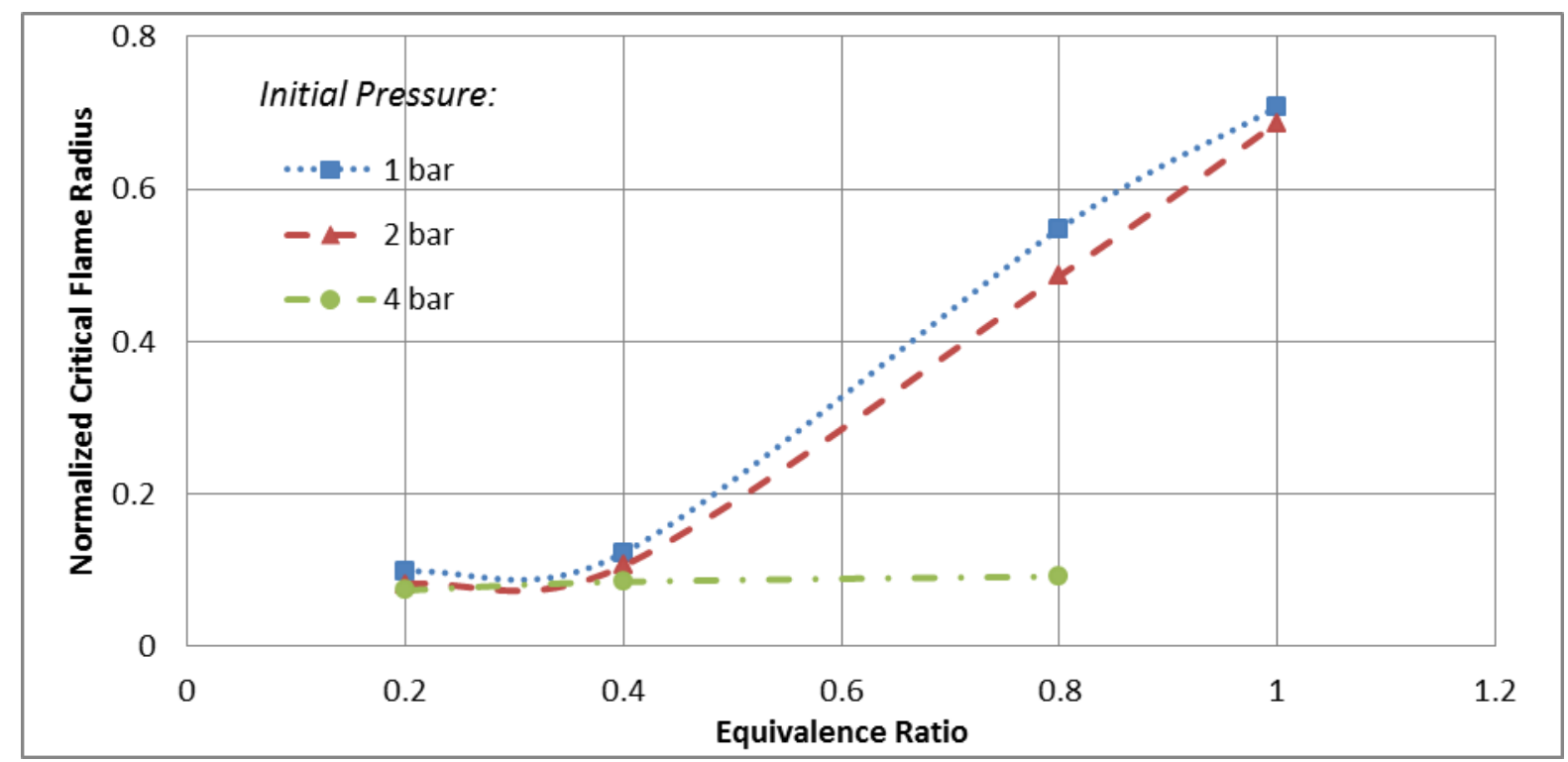

Fig.6 Normalized Critical Flame Radius under different equivalence ratio at an initial temperature of $348 \mathrm{~K}$

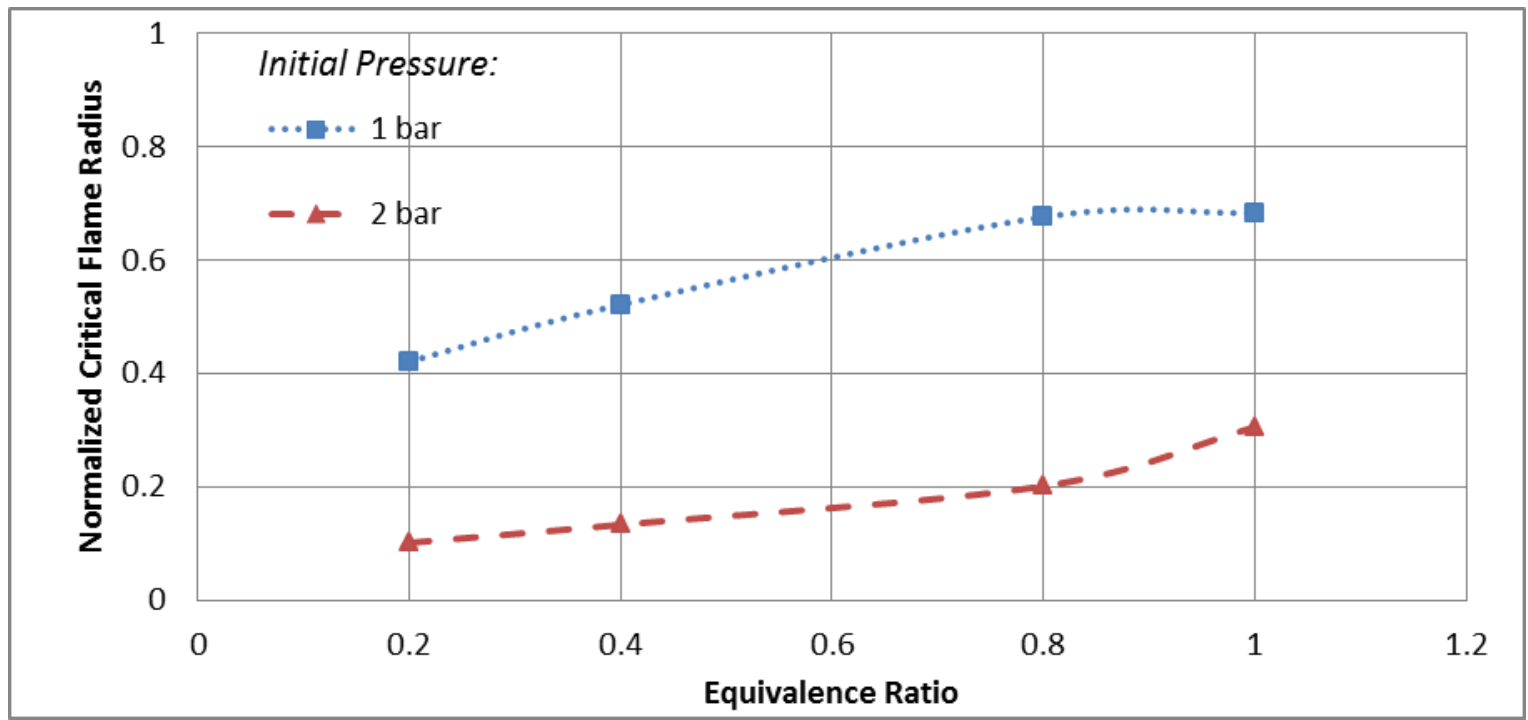

Fig.7 Normalized Critical Flame Radius under different equivalence ratio at an initial temperature of $423 \mathrm{~K}$ 


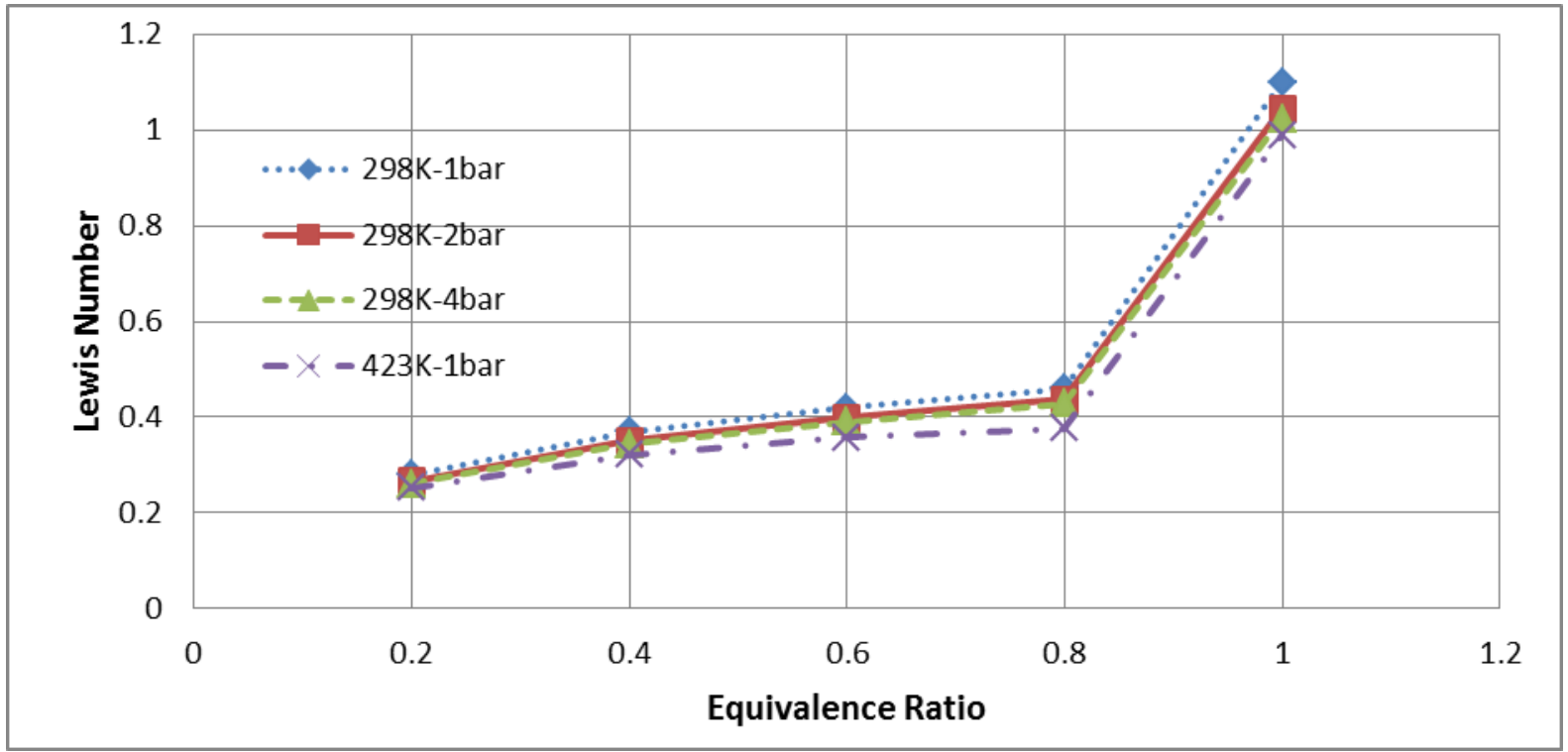

Fig. 8 Calculated Lewis Number under different equivalence ratio, temperature and pressure

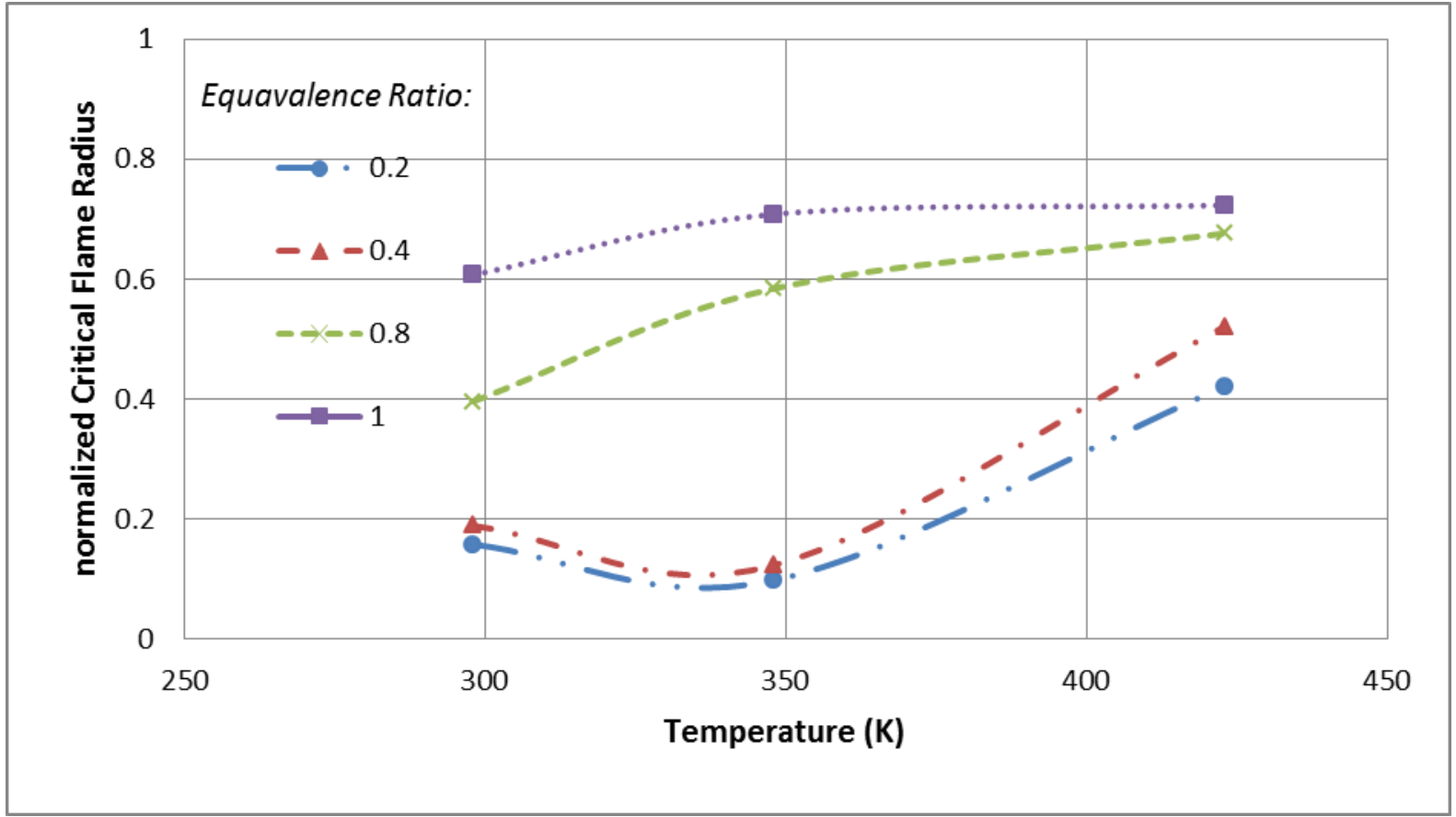

Fig.9 Critical Flame Radius under different temperature at an initial pressure of 1 bar 


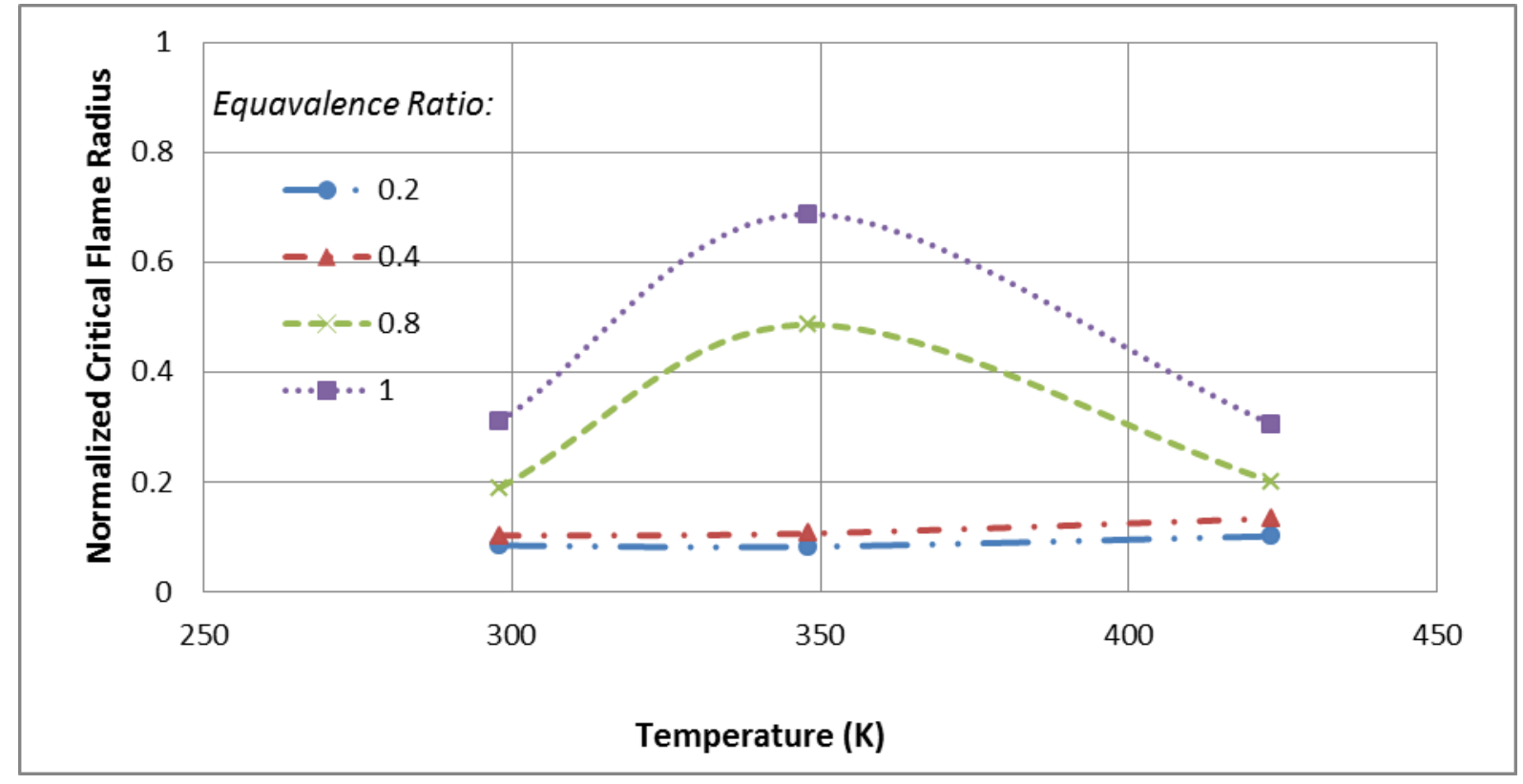

Fig.10 Critical Flame Radius under different temperature at an initial pressure of 2 bar

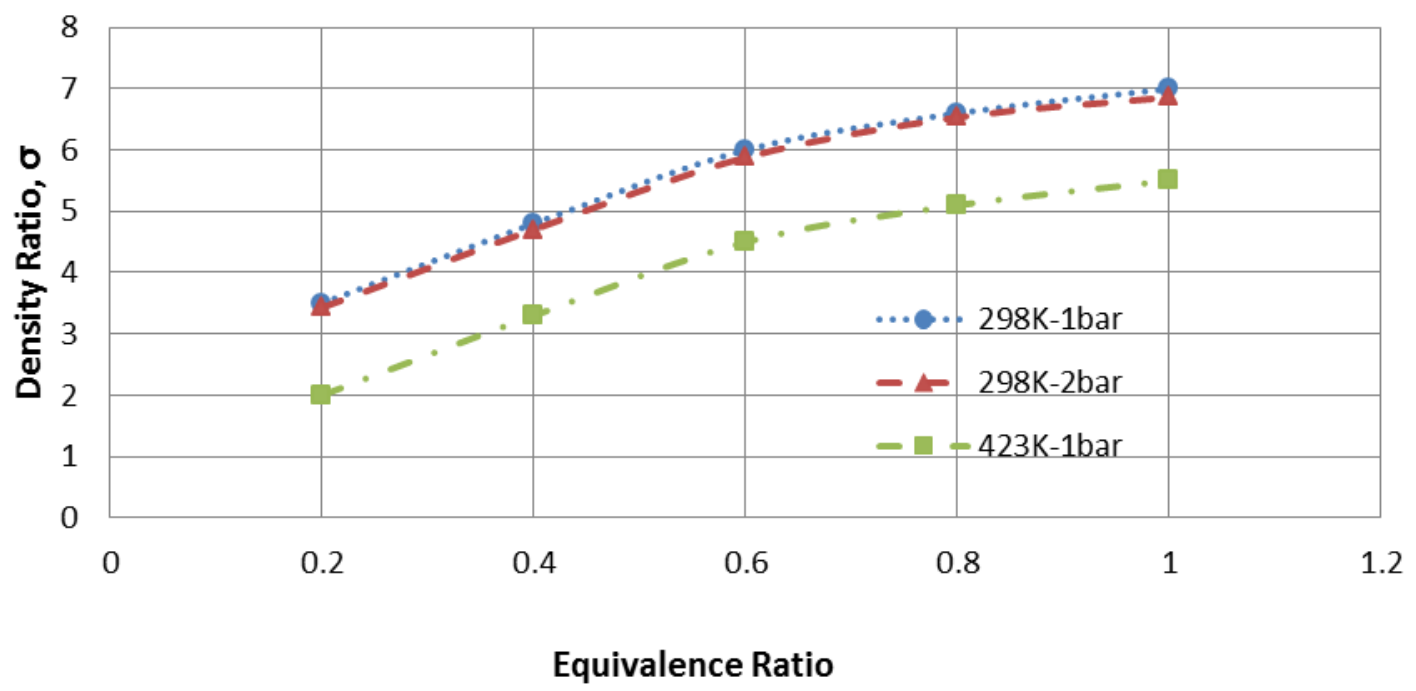

Fig.11 Calculated density ratio under different equivalence ratio, temperature and pressure 


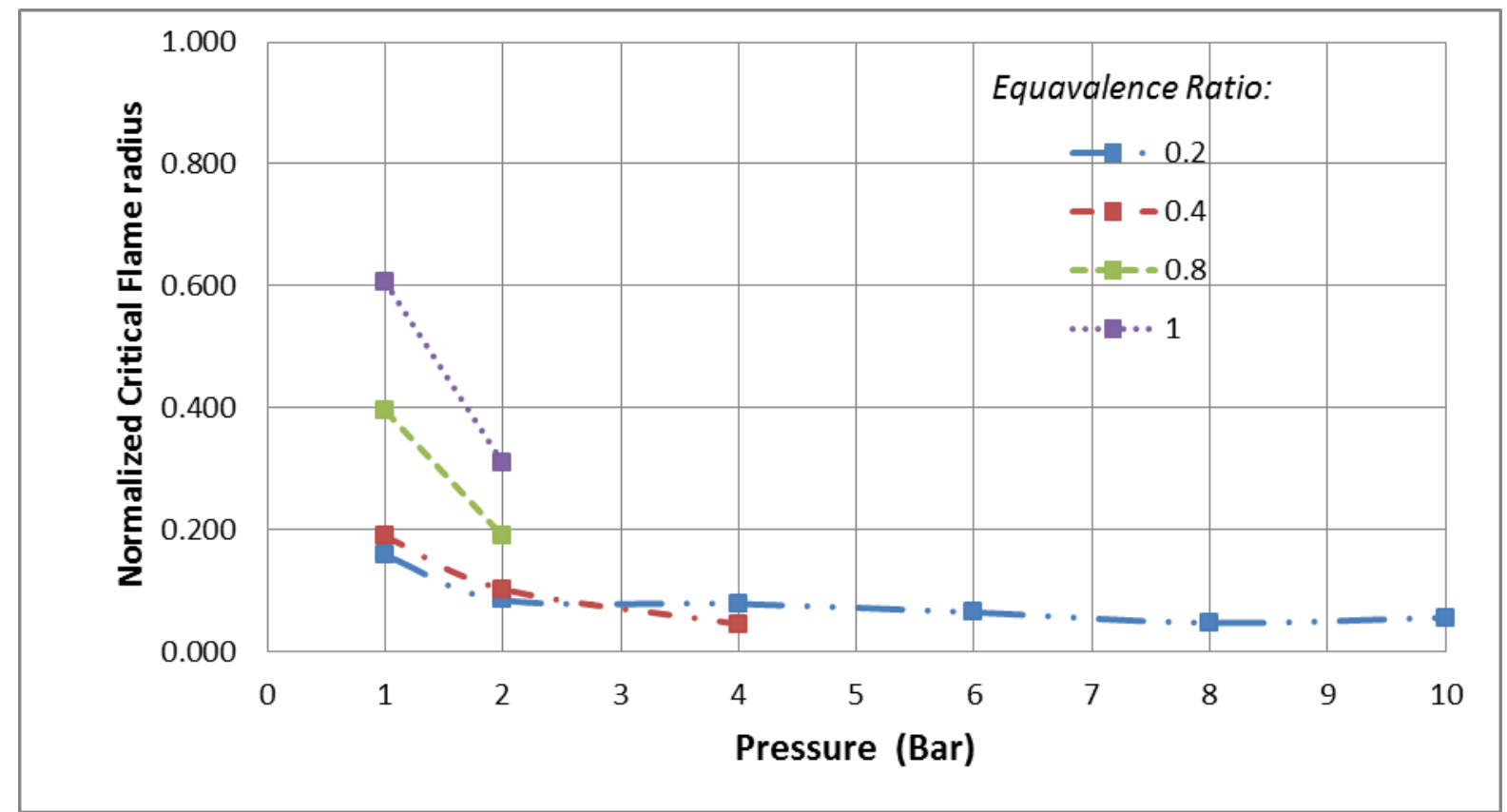

Fig.12 Critical Flame Radius under different equivalence ratios and pressures at an initial temperature of $298 \mathrm{~K}$

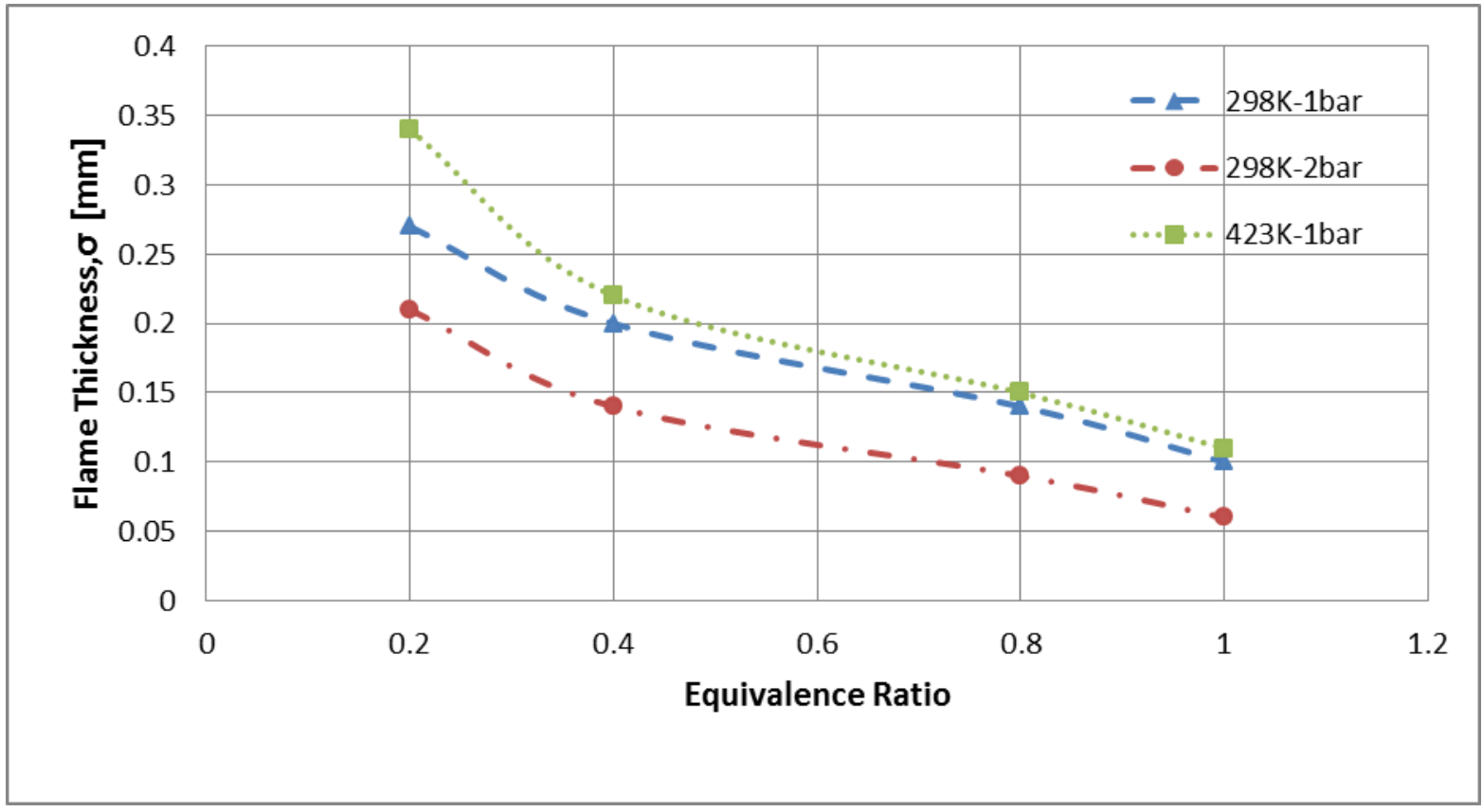

Fig.13 Measured Flame Thickness at different equivalence ratio, temperature and pressure 

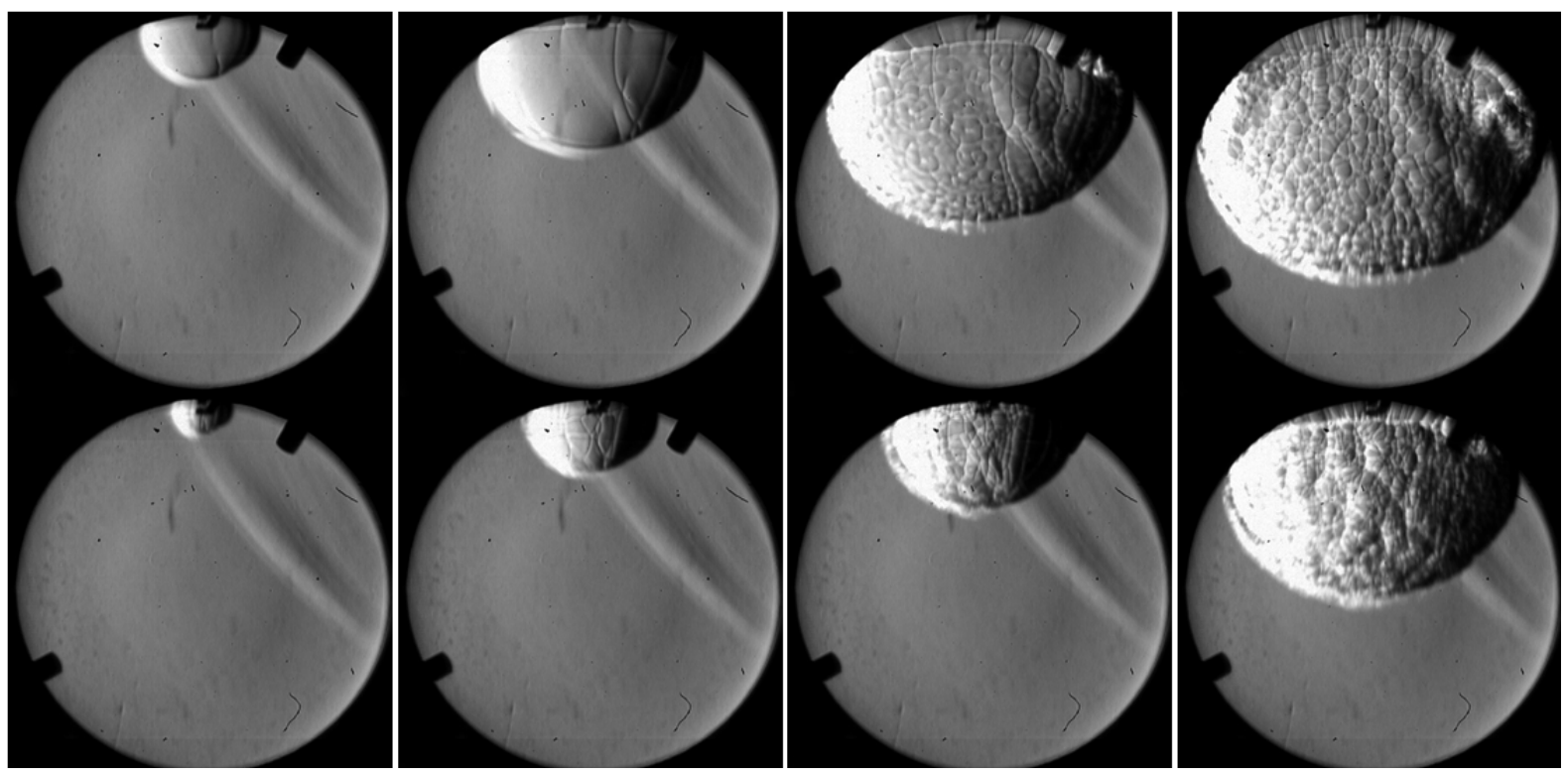

Fig.14 Schlieren photographs of burning sequences of stoichiometric hydrogen-air flames at 298K 1bar (upper row) and 2bar (lower row) at the same time after ignition: 1ms, 1.4ms, $2.5 \mathrm{~ms}$ and $3 \mathrm{~ms}$

\section{References:}

[1] Edmondson $\mathrm{H}$, Heap MP. The burning velocity of hydrogen-air flames. Combust Flame 1971;16:161-5.

[2] Stephenson PL, Taylor RG. Laminar flame propagation in hydrogen, oxygen, nitrogen mixtures. Combust Flame 1973;20:231-44.

[3] Law CK, Kwon OC. Effects of hydrocarbon substitution on atmospheric hydrogen-air flame propagation. Int J Hydrogen Energy 2004;29:867-79.

[4] Milton BE, Keck JC. Laminar burning velocities in stoichiometric hydrogen and hydrogenhydrocarbon gas mixtures. Combust Flame 1984;58:13-22.

[5] lijima T, Takeno T. Effects of temperature and pressure on burning velocity. Combust Flame 1986;65:35-43.

[6] Koroll GW, Kumar RK, Bowles EM. Burning velocities of hydrogen-air mixtures. Combust Flame 1993;94:330-40.

[7] Tse SD, Zhu DL, Law CK. Morphology and burning rates of expanding spherical flames in H2/O2/inert mixtures up to 60 atmospheres. Proc Combust Inst 2000;28:1793-800.

[8] Dahoe AE. Laminar burning velocities of hydrogen-air mixtures from closed vessel gas explosions. J Loss Prevention in the Process Industries 2005;18:152-66.

[9] Ilbas M, Crayford AP, Yilmaz L, Bowen PJ, Syred N. Laminar-burning velocities of hydrogen-air and hydrogen-methane-air mixtures: An experimental study. Int J Hydrogen Energy 2006;31:1768-79.

[10] Williams FA, Grcar JF. A hypothetical burning-velocity formula for very lean hydrogenair mixtures. Proc Combust Inst 2009;32:1351-7.

[11] Sun Z, Liu F, Bao X, Liu X. Research on cellular instabilities in outwardly propagating spherical hydrogen-air flames. Int J of Hydrogen Energy 2012; article in press. 
[12] Aung KT, Hassan MI, Faeth GM. Effects of pressure and nitrogen dilution on flame/stretch interactions of laminar premixed H2/O2/N2 flames. Combust Flame1998;112:1-15.

[13] Aung KT, Hassan MI, Faeth GM. Flame stretch interactions of laminar premixed hydrogen/air flames at normal temperature and pressure. Combust Flame 1997;109:1-24.

[14] Kwon OC, Faeth GM. Flame/stretch interactions of premixed hydrogen-fuelled flames: measurements and predictions. Combust Flame 2001;124:590-610.

[15] Bradley D, Harper CM. The development of instabilities in laminar explosion flames. Combust Flame 1994;99:562-72.

[16] Bradley D, Gaskell PH, Gu XJ. Burning velocities, Markstein lengths, and flame quenching for spherical methane-air flames: a computational study. Combust Flame 1996;104:176-98.

[17] Bradley D, Hicks RA, Lawes M, Sheppard CGW, Woolley R. The measurement of laminar burning velocities and Markstein numbers for iso-octane-air and iso-octane-nheptane-air mixtures at elevated temperatures and pressures in an explosion bomb. Combust Flame 1998;115:126-44.

[18] Tang C, Huang Z, Wang J, Zheng J. Effects of hydrogen addition on cellular instabilities of the spherically expanding propane flames. Int J Hydrogen Energy 2009;34:3483-87.

[19] Hu E, Huang Z, He J, Miao H. Experimental and numerical study on lean premixed methane-hydrogen-air flames at elevated pressures and temperatures. Int $\mathrm{J}$ Hydrogen Energy 2009;34:6951-60.

[20] Vu OTM, Park J, Kim JS, Kwon OB, Yun JH, Keel SI. Experimental study on cellular instabilities in hydrocarbon/hydrogen/carbon monoxide-air premixed flames. Int $\mathrm{J}$ Hydrogen Energy 2011;36:6914-24.

[21] Verhelst S. A Study of the Combustion in Hydrogen-Fuelled Internal Combustion Engines. Ph.D. thesis. Ghent University; 2005.

[22] Pareja J, Burbano HJ, Amell A, Carvajal J. Laminar burning velocities and flame stability analysis of hydrogen/air premixed flames at low pressure. Int $\mathrm{J}$ Hydrogen Energy 2011;36:6317-24.

[23] Kwon OC, Rozenchen G, Law CK. Cellular instabilities and self-acceleration of outwardly propagating spherical flames. Proc Combust Inst 2002;29:1775-83. 